\title{
A Comprehensive Profile Analysis of the Effect of Job Embeddedness on Turnover Intention among New Generation of Rural Migrant Workers in China: Based on PLS-SEM
}

\author{
Tang MeiRun \\ School of Business Management,College of Business, \\ Universiti Utara Malaysia, Sintok, Malaysia. \\ Jennie Soo Hooi Sin \\ School of Business Management, College of Business, \\ Universiti Utara Malaysia, Sintok, Malaysia. \\ Chuah Chin Wei \\ Othman Yeop Abdullah Graduate School of Business, \\ Universiti Utara Malaysia, Sintok Malaysia.
}

\begin{abstract}
This paper aimed to examine the relationship between organization embeddedness (OE), community embeddedness (CE) and turnover intention in the context of manufacturer sector in China. A 37-item questionnaire was filled by 384 new generation of rural migrant workers. Data were examined through a first-order of reflective model (SME1) and a two-stage of second-order reflective-formative hierarchical model (SME2) with the technical of Partial Least Squares. The empirical test results indicated that both $\mathrm{OE}$ and $\mathrm{CE}$ negative and significant related to turnover intention. When further disaggregated the components of $O E$ and $C E$ into the three subdimensions of fit, links, and sacrifice, this study found that causal indicator model of job embeddedness predict more variance of turnover intention than reflective model. Moreover, this study found that OEF, OES, CEF, and CES negative and significantly associated with turnover intention, while OEL positive related to turnover intention. Additionally, CEL did not show significant impact on turnover intention. The study concludes with several implications and recommendations for future research.
\end{abstract}

Keywords: Turnover Intention; Organization Embeddedness; Community Embeddedness; New Generation of Rural Migrant Workers; China.

\section{INTRODUCTION}

In terms of voluntary turnover, numbers of researchers have explored the turnover process (i.e. job attitudes, job alternative, and job search) and provided multivariate turnover models. However, previous studies have demonstrated that job attitudes variables (i.e., organizational commitment, job satisfaction) play a relative small role in explaining only $4 \%-5 \%$ of variance in turnover [1]. Other scholars have stressed that job alternatives and job search were weak predictions of turnover [1]. Same modest predictive strength (i.e. $5 \%$ to $25 \%$ of variance) of traditional turnover models in turnover was revealed in previous studies [2][3]. The modest predictive strength of traditional job attitudes, job alternative, job search, and traditional turnover models have inspired turnover scholars in exploring other new theories to gain insight into the turnover [4]. Theory of job embeddedness (JE) was characterized as one of these new viewpoints [5][6][7] which have been demonstrated its additional explanation 
variance in turnover [8]-[11], and generalized it to different context, such as European countries [12], Japan [13], Albanian employees [14], China [15], individualistic and collectivistic cultures [16]. The sheering number of the empirical studies about job embeddedness are inspiring, but the construct of job embeddedness still need to be addressed [6] [11].

Firstly, majority of previous job embeddedness researchers focused on organization embeddedness, while few focused on community aspects [6][17]. Secondly, documented literatures have showed mix results about the effect of job embeddedness on turnover across individual studies [16]. Studies conducted from USA [16][19][20][21][22], India [16], and Thailand [23] have indicated that organization embeddedness significantly predicted turnover, whereas community did not. In contrast, studies from [6][12][24] revealed that only community embeddedness significantly predicted turnover, but organization embeddedness did not show its significant relationship with turnover. Thirdly, job embeddedness researchers have claimed that only a handful of studies have examined the separate dimensions of fit, links and sacrifice both in organization and community embeddedness [8][23]. Previous researchers have stated that "a comparative research of reflective and a causal indicator model is interesting" [8]. Thus, further examination of the impact of community embeddedness, organization embeddedness, including the three sub-dimensions (links, fit and sacrifice) on turnover in a wider range of national, cultural and organizational context and respondents are needed [8][10][11][23]. Moreover, to date, in China, studies about job embeddedness are still limited and most of them are conducted among skilled employees [25]-[30]. The measurement of job embeddedness in these previous studies are adapted from Crosley's (2007) global scale, which primarily focused on organization embeddedness items that are widely regarded as ignoring the concern of community embeddedness items. Hence, it is of great importance to further explore the influence of the formative measurement of job embeddedness (community embeddedness and organization embeddedness) on turnover and extend to different types of respondents rather than skilled workers in China.

Therefore, current study aimed to investigate the influence of organization embeddedness and community embeddedness on turnover intention through a survey study targeting the sample of new generation of rural migrant workers ${ }^{1}$ (low-ranking, low skilled workers) in the manufacture sector of China. By disaggregate the components of organization embeddedness and community embeddedness into the three sub-dimensions of links, fit and sacrifice, recent study further studied the link between these components and turnover intention. The contributions for this study can be outlined in three aspects. Firstly, this study provided a comprehensive profile analysis of the effect of the separate composites (fit, links, and sacrifice) both in organization embeddedness and community embeddedness on turnover intention. Compared with the global reflective measurement of job embeddedness, the causal indicators completely capture the job embeddedness construct space, and different relationships were found across these dimensions. Secondly, this study responded to the call for more attention about the study of community embeddedness. It provided an insight into the scores for community embeddedness on turnover in different context. Thirdly, resent study extend the context of job embeddedness study to a low-ranking, low-skilled workers (i.e. new generation of rural migrant workers) in a non-western country of China.

\footnotetext{
${ }^{1}$ According to the definition of China's Official documents, rural migrant workers are the peasants who come from rural area and engage in non-agricultural works in cities [67]. Identified by the household registration system and land contract system in China, rural migrant workers work in non-agricultural sectors, but they still hold rural residents household registration and own farmland in their home countryside [54]. Rural migrant workers who were born after 1980s' are called new generation of rural migrant workers.
} 


\section{LITERATURE REVIEW AND HYPOTHESES DEVELOPMENT}

\section{Turnover}

Turnover is the process that an employee voluntarily and willingly terminated his/her organizational membership [31]. An individual's voluntary turnover behavior is result in his/her personal wishes, such as better job opportunities, family migration, physical health and other personal reasons, or may also other organizational factors from the alternative job opportunities, like much pay and benefits, promising promotion development and more comfortable working conditions. It is costly if firm frequently encounter employees' voluntary turnover [32]. The high costs of employees' turnover behavior manifest in the rising of recruiting, selecting, training new employees, and decreasing productive capacity and negative effects on performance, loose of proficiency, knowledge and skill [33]-[35]. Organizations that can effectively maintain human capital have more advantages than organizations that cannot [7].

Due to the difficult to measure actual voluntary turnover, researchers have explicitly stated that turnover intention is the most proximal and accurate precursor of actual voluntary turnover [36]-[40]. The assumption of intentions are the most immediate and accurate predictor of behavior has been confirmed in the theory of reasoned action [41] and the theory of planned behavior [42]. Prior researcher has pointed out that turnover intention is the next logistical stage after employee experienced job dissatisfaction, evaluation of expected utility of search and cost of quitting, following thinking of quitting and intention to search for alternatives [43]. In line with these assumptions, this study applies turnover intention as the similar construct of actual voluntary turnover behavior, and defined it as employees' overall performance or attitudes that they desire to leave their current organizations and search for other job opportunities, but the actual turnover behavior not yet happen.

In order to better understand individual's voluntary turnover decision-making process, scholars have explored numbers of voluntary turnover models, including (1) Participant's Turnover Decision-Making Model [44] (2) Employee Turnover Decision Process Model [43] (3) Turnover Factors Model [45] (4) Cusp Catastrophe Model of Employee Turnover [46] (5) The Unfolding Voluntary Turnover Model [47] (6) Combination Voluntary Turnover Model [48] (7) Voluntary Turnover Model. From the development of voluntary turnover models, we can found that these turnover studies were originally stem from March and Simon's central concepts: desirability of leaving (e.g. job satisfaction) and ease of movement (perceived job alternative). For a long time, most of the explanations of turnover studies follow three underlying assumptions, notably, (1) job dissatisfaction is a pervasive turnover cause, (2) dissatisfaction employees seek and leave for alternative (better) jobs, and (3) prospective leavers always compare alternatives to their current jobs based on a rational evaluation of their liner sequence SEUs [49]. Thus, job satisfaction and job alternatives are widely considered as prime turnover movers for a long time [49]. However, after years' development, turnover researchers have found that job attitudes variables (i.e. job satisfaction and organizational commitment), play a relatively small role in explaining only $4 \%-5 \%$ of variance in turnover behaviors [1]. At the same time, job alternatives and job search have been demonstrated that they are weak prediction of turnover [1]. In addition, same modest predictive strength (i.e. less than $5 \%$ to $25 \%$ of variance) in turnover of traditional turnover models has been revealed in previous studies [2][3].

\section{Job embeddedness}

Job embeddedness was defined as "the combined forces that keep an employee from leaving his or her job"[51] has been demonstrated its significant superiority in explaining turnover behaviors than traditional job attitudes variables, job search and job alternatives. The 
construct of job embeddedness was originally conceptualized as overall factors including psychological, social, and financial that make individuals stay at their current jobs [6]. These factors were categorized into organization and community embeddedness. Employee embedded in the organization and community is embedded in their current jobs. Specifically, organization embeddedness is conceptualized as work-related elements that remain an employee in his/her current job, while community embeddedness is operationalized as community related factors that directly bind an individual to his/her current job [5]. Community factors (i.e. family, safe neighborhood and compatibility with weather and local culture) are recognized as equal force to organization factors which bind employee to his/her current job. Furthermore, job embeddedness was operationalized into three critical subdimensions, namely fit, links and sacrifice, which include three by two matrix that reflects six dimensions: fit, links and sacrifice in organization and community.

\section{Fits}

Fit is defined "as the extent to which an individual's perception of compatibility or comfort with his/her organization and surrounding environment" [5]. It reflects the degree of an individual's personal interesting and values fit with his/her job, organization and community. Good organization-individual fit associate with an individual's personal values, plans and career goals of future, knowledge, skills, and abilities that are well-matched with the demands of his/her job and organizational culture. Furthermore, how well an individual fit with the community and surrounding environment also will influence his/her embeddedness in the organization and job. These aspects are independent of organization fits, including amenities, weather, culture, outdoor activities, religion, political and entertainment activities. The higher likelihood employee perceived fit with his/her organization and community, the more he/she will feel compatible and comfort to his /her organization, community and job [5].

\section{Links}

Links were originally characterized as the extent to which an individual formally and informally connect to a people and institutions or other people in a psychological, social and financial web including work and non-work groups, friends, communities and the physical environment in which individual lives [15]. The interaction between people and work team members, other colleagues and their supervisors constitute the links between people and their organizations. Thus, having a good relationship with work team members or colleges, and supervisors are associated with an individual's high organization links. The interaction between an individual and his or her friends, relatives who live with his/her in the same community, and social group constitute the links between an individual and his/her community. For example, being marriage and having children are parts of community links. Thus, having a spouse who are working in the community or having children whose schools are in the community are all associated with an individual's high community links. Mitchell et al., (2001) opinioned that the more strains and important an individual connect to the web, the more possibility an individual might embedded in his/her job and organization. However, these links might be population-specific different [5] [6].

\section{Sacrifice}

Sacrifice refers to the perception losses of material, psychological or social benefits when an individual leave his/her organization and community [5]. An individual will give up job-related benefits if he/she leave his/her job, such as stock options, pension compensation, colleagues, interesting projects and job advancement opportunities. Meanwhile, community sacrifice occurs if one has to relocate. Leaving a community might cause various community related conveniences losses, such as desirable home or community, local club membership and 
preferred geographical location. The more benefits people might give up when leave his/her organization or community, the more feeling of sacrifices when he/she leaves the job [5].

The above literature review lead to the following hypotheses:

H1: There is a negative and significant relationship between organization embeddedness and turnover intention

H1a: There is a negative and significant relationship between organization embeddedness fit and turnover intention

H1b: There is a negative and significant relationship between organization embeddedness links and turnover intention

H1c: There is a negative and significant relationship between organization embeddedness sacrifice and turnover intention

H2: There is a negative and significant relationship between community embeddedness and turnover intention.

H2a: There is a negative and significant relationship between community embeddedness fit and turnover intention.

H2b: There is a negative and significant relationship between community embeddedness links and turnover intention.

H2c: There is a negative and significant relationship between community embeddedness sacrifice and turnover intention.

\section{RESEARCH FRAMEWORK}

Guided by the prior literature reviews, this study proposed two research frameworks which were depicted as figure 1 and figure 2 .

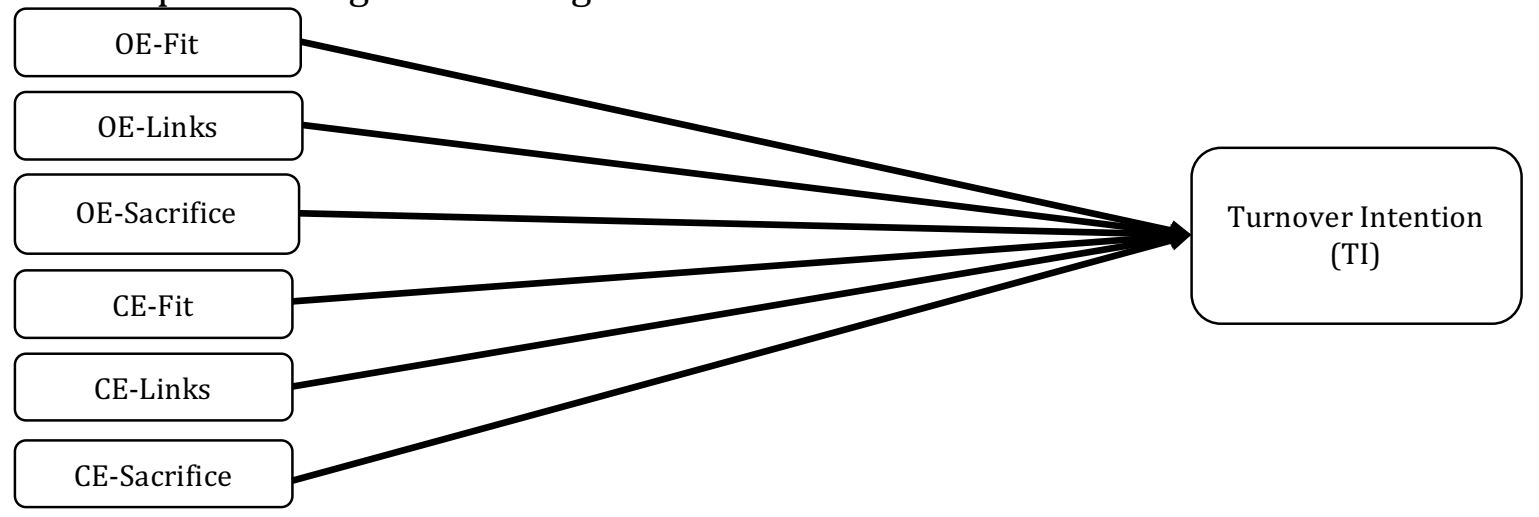

Figure 1

Research Framework 1

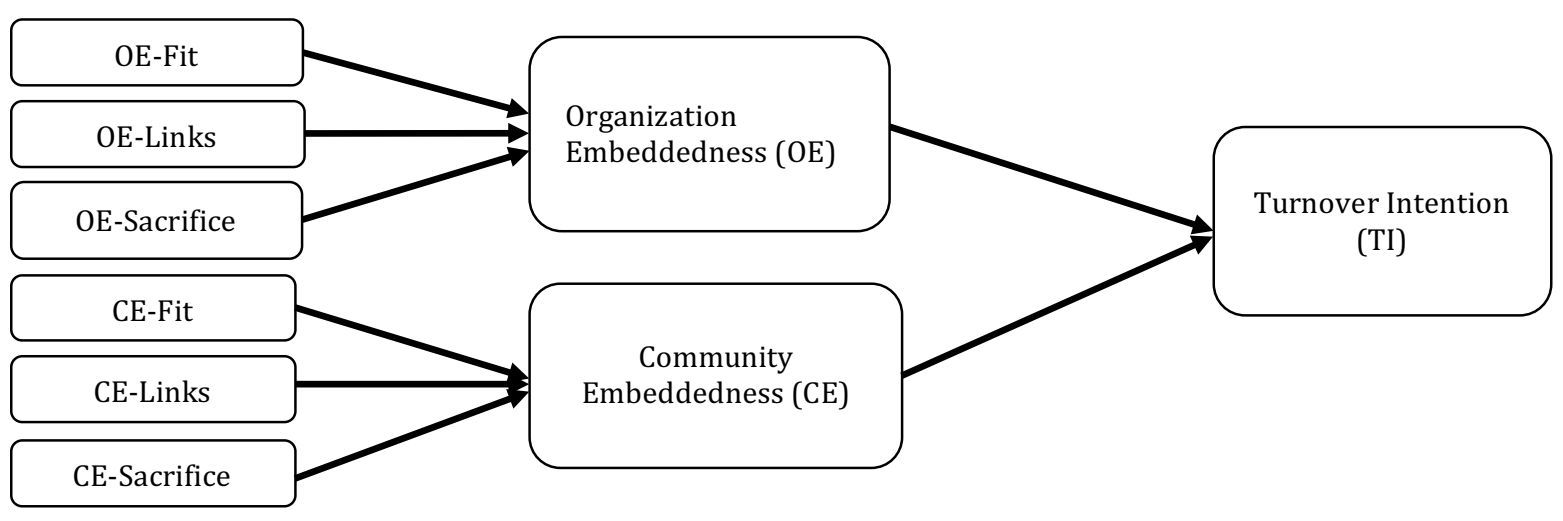

Figure 2

Research Framework 2 


\section{Respondents and Data Collection Procedure}

\section{DATA ANALYSIS}

Respondents in current study targeted new generation of rural migrant workers who are working in manufacturer sector of China. As an key part of labor supply in China, new generation of rural migrant workers were highlighted as industrial workers [52]. According to the reports from China National Statistics Bureau (2016), there were 281.71 million rural migrant workers accounting for $36.3 \%$ of the total labor force (776.03 million) by the end of year 2016 in China. Among this large number, there were 140 million new generation of rural migrant workers accounting to $49.7 \%$ of the total number of rural migrant workers. The large number shift from farming labor to non-agriculture sectors provided low cost labor force and created labor force comparative advantage to China's industries development [53]. To same extend, new generation of rural migrant workers extremely contributed to China's high-speed economic development and promote the society transform from an agricultural to an industrial society [54]. Unfortunately, rural migrant workers have showed high voluntary turnover behaviors for a long time and currently evolved into short-term employment trend. In terms of new generation of rural migrant workers, who are born after 1980's and 1990's, their job duration are only 1.5 and 0.9 years respectively (Zhang, 2016).

Data was collected from November 2017 to March 2018 in 7 factories in Guizhou province which is located at southwest of mainland China. By assistance of the managers from each human resource department in the factory described the purpose of this study to the new generation of rural migrant workers, the respondents complete the questionnaire voluntarily and anonymously within two days. 600 questionnaires were distributed out of which 384 questionnaires were finalized for this study. The sample contain 217 male (56.5\%) and 167 female (43.5\%). 125 (32.6\%) of these respondents are 16 to 26 years old, while, $259(67.4 \%)$ of them are in the age of 27 to 37. The sample consist of $192(50 \%)$ married, $172(44.8 \%)$ single, and 20 (5.2\%) divorce. With respect to education, $131(34.1 \%)$ and $90(23.4 \%)$ are educated in the level of secondary school and high school respectively, while 65 (16.9\%) and $83(21.6 \%)$ achieved secondary technical school and Junior college education respectively. In terms of organizational tenure, there are 199 (51.8\%) work on current factory for 3 or more years. Whereas, 49 (12.8\%), 72 (18.8\%), 72 (19\%) and $64(16.8 \%)$ of them have been working in their current companies for 12 to 18 months, 6 to 12 months and less than 6 months respectively. In this sample, 95 (24.7\%) did not change their jobs before, however 113 (29.4\%), $95(24.7 \%)$ and $81(21.1 \%)$ of them have one time, two times and three times job quite experience before.

\section{Measurement}

Six items taken from [56][57] were used to measured turnover intention. Organization embeddedness and community embeddedness were operationalized from [5] and [27]. A final scale of 17-item of organization embeddedness and 14-item of community embeddedness were implied in current study. Answers were elicited on a 7-point Likert scale ranging from 7= 'strongest agree' to 1 = 'strongly disagree'. These variables scales were originally written in English, and accomplished into Chinese version through a multistage translation and backtranslation procedure suggested by Brislin (1980).

\section{Data Analysis}

Data received from the respondents were loaded into Partial Least Squares (PLS) to analysis the Structural Equation Model (SEM) and tested the hypotheses. Measurement model assessment (outer model) and structural model (inner model) were investigated in this study. 


\section{Assessment of Measurement Model}

In terms of the measurement model assessment, a two-stage approach including first-order reflective measurement model and a second-order formative measurement model were examined in this section.

\section{Reflective Measurement Assessment}

In the reflective measurement assessment, indicator reliability, internal consistency reliability, convergent validity, and discriminant validity were investigated in this study. In specific, Cronbach Alpha, indicator loadings, composite reliability (CR), average variance extracted (AVE), cross-Loadings, Fornell-Larcker, and Heterotrait-Monotrait ratio (HTMT) were reported in this section. According to [59], the acceptable value of Cronbach Alpha should be 0.7 or higher. \{Formatting Citation\} suggested that the common rule of thumb is that the composite reliability value, and standardized outer loadings should be at least 0.60 , and 0.708 or above respectively. An AVE value of 0.50 or higher is the criterion that indicates the construct explains more than half of the variance of its indicators [60]. Table 2, table 3, table 4, and table 5 shows the results of the first-order reflective measurement model from Smart-PLS 3.2.7.

Based on table 2, we found the loadings of items in the model have achieved the rule of thumb value suggested as 0.708. However, two item (OEL1 and OEL4) loading (0.698 and 0.648) were below 0.708 , but higher than 0.4. According to [60], indicators with outer loadings between 0.40 and 0.70 should be considered for removal from the scale only when deleting the indicators leads to an increasing of composite reliability above the suggested threshold value. However, according to table 3, the construct of OEL CR value is 0.852 , which is higher than the standard cut-off value of 0.708 . Hence, we still consider retain these two items in current study. 
Table2. Indicator loadings and Crossing Loadings.

\begin{tabular}{|c|c|c|c|c|c|c|c|}
\hline & CEF & CEL & CES & $\mathrm{OEF}$ & OEL & OES & TI \\
\hline CEF1 & 0.866 & 0.475 & 0.389 & 0.351 & 0.406 & 0.474 & -0.385 \\
\hline CEF2 & 0.835 & 0.384 & 0.327 & 0.275 & 0.356 & 0.36 & -0.326 \\
\hline CEF3 & 0.853 & 0.408 & 0.298 & 0.238 & 0.326 & 0.363 & -0.296 \\
\hline CEF4 & 0.804 & 0.477 & 0.208 & 0.311 & 0.398 & 0.399 & -0.24 \\
\hline CEF5 & 0.879 & 0.488 & 0.33 & 0.433 & 0.408 & 0.499 & -0.412 \\
\hline CEF6 & 0.891 & 0.506 & 0.352 & 0.424 & 0.405 & 0.494 & -0.415 \\
\hline CEL1 & 0.46 & 0.834 & 0.378 & 0.476 & 0.525 & 0.525 & -0.341 \\
\hline CEL2 & 0.423 & 0.797 & 0.363 & 0.296 & 0.415 & 0.328 & -0.18 \\
\hline CEL3 & 0.473 & 0.895 & 0.354 & 0.251 & 0.371 & 0.378 & -0.276 \\
\hline CEL4 & 0.465 & 0.885 & 0.365 & 0.241 & 0.382 & 0.361 & -0.264 \\
\hline CES1 & 0.24 & 0.358 & 0.82 & 0.341 & 0.346 & 0.316 & -0.348 \\
\hline CES2 & 0.252 & 0.277 & 0.793 & 0.267 & 0.241 & 0.21 & -0.273 \\
\hline CES3 & 0.4 & 0.394 & 0.837 & 0.272 & 0.284 & 0.291 & -0.407 \\
\hline CES4 & 0.33 & 0.359 & 0.841 & 0.23 & 0.262 & 0.214 & -0.4 \\
\hline OEF1 & 0.365 & 0.325 & 0.304 & 0.876 & 0.57 & 0.592 & -0.472 \\
\hline OEF2 & 0.331 & 0.333 & 0.296 & 0.859 & 0.541 & 0.49 & -0.4 \\
\hline OEF3 & 0.314 & 0.356 & 0.271 & 0.855 & 0.577 & 0.497 & -0.389 \\
\hline OEF4 & 0.263 & 0.329 & 0.201 & 0.717 & 0.531 & 0.45 & -0.264 \\
\hline OEF5 & 0.423 & 0.365 & 0.309 & 0.865 & 0.567 & 0.507 & -0.481 \\
\hline OEF6 & 0.311 & 0.286 & 0.282 & 0.825 & 0.588 & 0.447 & -0.374 \\
\hline OEF7 & 0.319 & 0.235 & 0.257 & 0.801 & 0.499 & 0.434 & -0.356 \\
\hline OEL1 & 0.391 & 0.441 & 0.26 & 0.373 & 0.698 & 0.394 & -0.147 \\
\hline OEL2 & 0.306 & 0.36 & 0.285 & 0.493 & 0.759 & 0.459 & -0.158 \\
\hline OEL3 & 0.292 & 0.401 & 0.237 & 0.629 & 0.81 & 0.526 & -0.244 \\
\hline OEL4 & 0.266 & 0.291 & 0.153 & 0.502 & 0.648 & 0.432 & -0.117 \\
\hline OEL5 & 0.386 & 0.355 & 0.3 & 0.431 & 0.737 & 0.322 & -0.264 \\
\hline OES1 & 0.368 & 0.361 & 0.227 & 0.516 & 0.493 & 0.799 & -0.274 \\
\hline OES2 & 0.484 & 0.455 & 0.337 & 0.58 & 0.533 & 0.856 & -0.42 \\
\hline OES3 & 0.383 & 0.389 & 0.201 & 0.497 & 0.51 & 0.839 & -0.28 \\
\hline OES4 & 0.384 & 0.368 & 0.239 & 0.426 & 0.41 & 0.859 & -0.35 \\
\hline OES5 & 0.518 & 0.448 & 0.297 & 0.484 & 0.482 & 0.884 & -0.391 \\
\hline TI1 & -0.369 & -0.274 & -0.415 & -0.418 & -0.23 & -0.381 & 0.921 \\
\hline $\mathrm{TI} 2$ & -0.324 & -0.268 & -0.449 & -0.417 & -0.233 & -0.344 & 0.907 \\
\hline TI3 & -0.372 & -0.302 & -0.365 & -0.492 & -0.279 & -0.436 & 0.902 \\
\hline TI4 & -0.393 & -0.315 & -0.362 & -0.43 & -0.272 & -0.365 & 0.89 \\
\hline TI5 & -0.38 & -0.276 & -0.356 & -0.404 & -0.214 & -0.324 & 0.882 \\
\hline TI6 & -0.412 & -0.318 & -0.439 & -0.439 & -0.255 & -0.386 & 0.906 \\
\hline
\end{tabular}

With respect to internal consistency, table 3 displays that the CR values of all the constructs in this study were higher than o.6. Hence, all the constructs in the reflective measurement model have reached internal consistency. On the other hand, table 3 also shows that the AVE value of all construct were higher than 0.50 . Therefore, all the constructs in the reflective measurement model have achieved convergent validity. 
MeiRun, T., Sin, J. S. H., \& Wei, C. C. (2018). A Comprehensive Profile Analysis of the Effect of Job Embeddedness on Turnover Intention among New Generation of Rural Migrant Workers in China: Based on PLS-SEM. Advances in Social Sciences Research Journal, 5(8) $264-279$.

Table 3. Findings of the measurement model (First Order, Reflective).

\begin{tabular}{|c|c|c|c|}
\hline & Alpha & CR & AVE \\
\hline OEF & 0.925 & 0.939 & 0.689 \\
\hline OEL & 0.792 & 0.852 & 0.537 \\
\hline OES & 0.903 & 0.927 & 0.719 \\
\hline CEL & 0.878 & 0.915 & 0.729 \\
\hline CES & 0.843 & 0.893 & 0.677 \\
\hline TI & 0.954 & 0.963 & 0.812 \\
\hline
\end{tabular}

Moreover, table 4, table 5 depict the results of the assessment of discriminant validity regarding to Fornell-Larcker criterion, and Heterotrait-Monotrait Ratio (HTMT). According to [60], discriminant validity is established when (1) an indicator's outer loading on the associated construct is greater than any of its cross-loadings (i.e., its correlation) on other constructs. (2) Fornell-Larcker criterion should be greater than its highest correlation with any other construct (3) a disattenuated correlation between two constructs close to 1 indicates a lack of discriminant validity. Hence, based on Table 2, table 4, and table 5 this study has achieved all threshold values in cross-loadings, Fornell-Larcker and Heterotrait-Monotrait ratio (HTMT) in the external consistency.

Table4. Discriminant Validity of Fornell-Larcker Criterion.

\begin{tabular}{|c|c|c|c|c|c|c|c|}
\hline & CEF & CEL & CES & OEF & OEL & OES & TI \\
\hline CEF & $\mathbf{0 . 8 5 5}$ & & & & & & \\
\hline CEL & 0.535 & $\mathbf{0 . 8 5 4}$ & & & & & \\
\hline CES & 0.379 & 0.428 & $\mathbf{0 . 8 2 3}$ & & & & \\
\hline OEF & 0.406 & 0.384 & 0.335 & $\mathbf{0 . 8 3}$ & & & \\
\hline OEL & 0.449 & 0.503 & 0.345 & 0.664 & $\mathbf{0 . 7 3 3}$ & & \\
\hline OES & 0.512 & 0.482 & 0.315 & 0.591 & 0.571 & $\mathbf{0 . 8 4 8}$ & \\
\hline TI & -0.416 & -0.324 & -0.442 & -0.481 & -0.275 & -0.415 & $\mathbf{0 . 9 0 1}$ \\
\hline
\end{tabular}

Table5. Discriminant Validity of Heterotrait-Monotrait Ratio (HTMT)

\begin{tabular}{|c|c|c|c|c|c|c|c|}
\hline & CEF & CEL & CES & OEF & OEL & OES & TI \\
\hline CEF & & & & & & & \\
\hline CEL & $\mathbf{0 . 5 8 8}$ & & & & & & \\
\hline CES & 0.409 & $\mathbf{0 . 4 8 8}$ & & & & & \\
\hline OEF & 0.422 & 0.41 & $\mathbf{0 . 3 7 8}$ & & & & \\
\hline OEL & 0.518 & 0.59 & 0.408 & $\mathbf{0 . 7 7 2}$ & & & \\
\hline OES & 0.541 & 0.517 & 0.35 & 0.643 & $\mathbf{0 . 6 8 6}$ & & \\
\hline TI & 0.429 & 0.339 & 0.482 & 0.501 & 0.289 & $\mathbf{0 . 4 3 4}$ & \\
\hline
\end{tabular}

\section{Formative Measurement Assessment}

In terms of formative measurement assessment, this study investigated the potential collinearity problem, and the significance for outer weights of each indicator to the formative construct. A variance inflation factor (VIF) with 5 or higher respectively indicates a potential collinearity problem [61]. Table 6 indicates the results the formative measurement assessment. Based on this table, this study found that all the constructs in the formative measure model did not have collinearity problems. Additional, table 6 also shows that indicator of community embeddedness links (CEL) was not significant ( $t$-value=0.707) to its formative construct. However, due to its high significant of outer loading ( $t$-value $=7.742$, above 0.50), we retain this indicators. Therefore, the current study has achieved all threshold values of the formative measurement (organization and community embeddedness), and a further analysis of the structural model can continue. 
Table6. Findings of Measurement Model for Formative construct (Organization, Community Embeddedness.)

\begin{tabular}{|c|c|c|c|c|c|}
\hline & $\begin{array}{c}\text { Outer } \\
\text { weights }\end{array}$ & $\begin{array}{c}\text { T-Values } \\
\text { 2-tailed }\end{array}$ & $\begin{array}{c}\text { Outer } \\
\text { Loadings }\end{array}$ & $\begin{array}{c}\text { T-Values } \\
\text { 2-tailed }\end{array}$ & VIF(outer) \\
\hline OEF & 0.925 & 25.042 & 0.925 & 25.042 & 2.032 \\
\hline OEL & 0.528 & 6.161 & 0.528 & 6.161 & 1.962 \\
\hline OES & 0.797 & 13.033 & 0.797 & 13.033 & 1.684 \\
\hline CEF & 0.525 & 5.401 & 0.803 & 13.336 & 1.458 \\
\hline CEL & 0.079 & $0.707(\mathrm{NS})$ & 0.626 & 7.742 & 1.528 \\
\hline CES & 0.620 & 6.857 & 0.853 & 17.735 & 1.273 \\
\hline
\end{tabular}

\section{Assessment of Structural Model}

This part investigated structural model collinearity issues, $\mathrm{R}^{2}$ level, $\mathrm{f}^{2}$ effect sizes, predictive relevance $\mathrm{Q}^{2}, \mathrm{q}^{2}$ effect sizes, and significance and relevance of the structural model relationships. A VIF value of 5 or higher is considered as critical levels of collinearity [61]. Table 7 indicates the collinearity assessment of current study's structural model. From table 7 we can conclude that the VIF values in current study are clearly below the threshold of 5. Thus, there are no collinearity problems in current structural model. Further evaluations about the coefficient of determination $\left(\mathrm{R}^{2}\right)$, predictive relevance $\left(\left(\mathrm{Q}^{2}\right)\right.$ and effect size $\left(\mathrm{f}^{2}, \mathrm{q}^{2}\right)$ can continue.

Table7. Inner VIF Values.

\begin{tabular}{|c|c|c|}
\hline & TI & Collinearity Problems \\
\hline OE & 1.284 & No \\
\hline CE & 1.284 & No \\
\hline
\end{tabular}

\section{The Coefficient of Determination $\left(R^{2}\right)$, Predictive Relevance $\left(Q^{2}\right)$ and Effect Size $\left(f^{2}, q^{2}\right)$}

With respect to evaluate the model's predictive power, resent study assess the coefficient of determination ( $\mathrm{R}^{2}$ value). The value of $\mathrm{R}^{2}$ was characterized as the combined effects of the exogenous latent variables on the endogenous latent variable [60]. $\mathrm{R}^{2}$ values of $0.75,0.50$, or 0.25 for endogenous latent variables respectively represent the substantial, moderate, or weak coefficient of determination [61][62]. In addition, this study evaluate the effect size of the predictor constructs using Cohen's $f^{2}$ [63]. The value of $f^{2}\left[f^{2}=\left(R^{2}\right.\right.$ include- $R^{2}$ exclude $) /(1$ $\mathrm{R}^{2}$ include)] assesses how strong the exogenous variable's contribution into $\mathrm{R}^{2}$ values of the endogenous variable. The $f^{2}$ value of $0.02,0.15$, and 0.35 represent small, medium, and large effects (Cohen, 1988) of exogenous latent variable respectively, while effect size value of less than 0.02 indicate that there is no effect. Moreover, current study assesses the predictive relevance $\left(\mathrm{Q}^{2}\right)$ of the path model and its effect size $\left(\mathrm{q}^{2}\right)$. The value of $\mathrm{Q}^{2}$ with larger than 0 indicate the exogenous variable have predictive relevance for the endogenous variable, while the effect size of $\mathrm{q}^{2}\left[\mathrm{q}^{2}=\left(\mathrm{Q}^{2}\right.\right.$ include - $\mathrm{Q}^{2}$ exclude $) /\left(1-\mathrm{Q}^{2}\right.$ include $\left.)\right]$ allows assessing a certain exogenous variable's contribution to an endogenous variable's $Q^{2}$ value. The $q^{2}$ value of 0.02 , 0.15 , and 0.35 respectively represent small, medium, and large predictive relevance of exogenous variable for a certain endogenous latent variable. Table 7 illustrates the coefficient of determination $\left(R^{2}\right)$, predictive relevance $\left(Q^{2}\right)$, and their effect size $\left(f^{2}, q^{2}\right)$. 
MeiRun, T., Sin, J. S. H., \& Wei, C. C. (2018). A Comprehensive Profile Analysis of the Effect of Job Embeddedness on Turnover Intention among New Generation of Rural Migrant Workers in China: Based on PLS-SEM. Advances in Social Sciences Research Journal, 5(8) $264-279$.

Table7. The Coefficient of Determination $\left(R^{2}\right)$, Predictive Relevance $\left(Q^{2}\right)$, and Effect Size $\left(f^{2}, q^{2}\right)$.

\begin{tabular}{|c|c|c|c|c|c|c|}
\hline $\begin{array}{c}\text { Endogenous } \\
\text { Latent Variable }\end{array}$ & $\mathrm{R}^{2}$ (SEM1) & $\mathrm{R}^{2}$ (SEM2) & \multicolumn{2}{|c|}{$\mathrm{Q}^{2}$ (SEM1) } & \multicolumn{2}{|c|}{$\mathrm{Q}^{2}$ (SEM2) } \\
\hline TI & 0.382 & 0.367 & \multicolumn{2}{|c|}{0.287} & \multicolumn{2}{|c|}{0.342} \\
\hline $\begin{array}{c}\text { Exogenous } \\
\text { Latent Variable }\end{array}$ & $\mathrm{f}^{2}$ & Effect size & $\mathrm{Q}^{2}$ include & $\mathrm{Q}^{2}$ exclude & $\mathrm{q}^{2}$ & Effect size \\
\hline OEF & 0.122 & $\begin{array}{l}\text { Small to } \\
\text { Medium }\end{array}$ & 0.287 & 0.230 & 0.080 & $\begin{array}{c}\text { Small to } \\
\text { Medium }\end{array}$ \\
\hline OEL & 0.048 & $\begin{array}{l}\text { Small to } \\
\text { Medium }\end{array}$ & 0.287 & 0.265 & 0.031 & $\begin{array}{c}\text { Small to } \\
\text { Medium }\end{array}$ \\
\hline OES & 0.015 & No effect & 0.287 & 0.280 & 0.010 & No effect \\
\hline CEF & 0.034 & $\begin{array}{l}\text { Small to } \\
\text { Medium }\end{array}$ & 0.287 & 0.271 & 0.022 & Small \\
\hline CEL & 0.000 & No effect & 0.287 & 0.287 & 0.000 & No effect \\
\hline CES & 0.095 & $\begin{array}{l}\text { Small to } \\
\text { Medium }\end{array}$ & 0.287 & 0.243 & 0.062 & $\begin{array}{c}\text { Small to } \\
\text { Medium }\end{array}$ \\
\hline OE & 0.155 & Medium & 0.342 & 0.252 & 0.137 & $\begin{array}{c}\text { Small to } \\
\text { Medium }\end{array}$ \\
\hline CE & 0.152 & Medium & 0.342 & 0.256 & 0.131 & $\begin{array}{c}\text { Small to } \\
\text { Medium }\end{array}$ \\
\hline
\end{tabular}

\section{Assessment of Structural Model Path Coefficients}

Recent study used two-tailed tests of significance level $5 \%$ to test the hypotheses. Thus, a critical t-value of 1.96 is considered as the threshold to examine the hypotheses in our current study [60]. In addition, researchers have claimed that using T-values and p-values is not sufficient when reporting the significance of the structural model relationships. When performing bootstrapping test, the confidence intervals bias corrected result of upper and lower bound should be out of 0 point [60]. Table 9 indicates the results of the structural Model Path Coefficient.

Table9. Results of the Structural Model Path Coefficient.

\begin{tabular}{|c|c|c|c|c|c|c|c|}
\hline \multirow{2}{*}{ Hypotheses } & \multirow{2}{*}{ Relationship } & \multirow{2}{*}{ Beta } & \multirow{2}{*}{$\begin{array}{l}\text { T-Values } \\
\text { 2-tailed }\end{array}$} & \multirow{2}{*}{ P-Values } & \multicolumn{2}{|c|}{$\begin{array}{l}\text { Confidence Interval } \\
\text { (BC) }\end{array}$} & \multirow{2}{*}{ Decisions } \\
\hline & & & & & $\begin{array}{c}\mathrm{LL} \\
(2.5 \%) \\
\end{array}$ & $\begin{array}{c}\text { UL } \\
(97.5 \%)\end{array}$ & \\
\hline 1 & $\mathrm{OE}->\mathrm{TI}$ & -0.355 & 7.164 & 0.000 & -0.445 & -0.248 & Supported \\
\hline 2 & OEF $->\mathrm{TI}$ & -0.394 & 6.518 & 0.000 & -0.512 & -0.276 & Supported \\
\hline 3 & OEL $->\mathrm{TI}$ & 0.252 & 4.080 & 0.000 & 0.145 & 0.388 & Not Supported \\
\hline 4 & OES -> TI & -0.135 & 2.012 & 0.044 & -0.267 & -0.005 & Supported \\
\hline 5 & CE -> TI & -0.351 & 6.581 & 0.000 & -0.454 & -0.245 & Supported \\
\hline 6 & $\mathrm{CEF}->\mathrm{TI}$ & -0.186 & 3.279 & 0.001 & -0.301 & -0.075 & Supported \\
\hline 7 & CEL -> TI & -0.017 & 0.288 & 0.773 & -0.128 & 0.100 & Not supported \\
\hline 8 & CES -> TI & -0.277 & 5.159 & 0.000 & -0.377 & -0.169 & Supported \\
\hline
\end{tabular}

From table 9, recent study has found the negative and significant relationship among organization embeddedness and turnover intentions $(\beta=-0.355, t=7.164, p=0)$, community embeddedness and turnover intention $(\beta=-0.351, t=6.581, p=0)$, organization embeddedness fit and turnover intentions $(\beta=-0.394, t=6.518, p=0)$, organization embeddedness sacrifice and turnover intention $(\beta=-0.135, \mathrm{t}=2.012, \mathrm{p}=0.044)$, community embeddedness fit and turnover intentions $(\beta=-0.186, t=3.2799, p=0.001)$, and community embeddedness sacrifice 
and turnover intentions $(\beta=-0.277, t=5.159, p=0)$. Hence, hypotheses $1,2,4,5,6$, and 8 all were supported. However, this study found that organization embeddedness links positively and significantly predict turnover intention $(\beta=0.252, t=4.080, p=0)$. Hence, hypothesis 3 was rejected. Moreover, there was not significant relationship between community embeddedness links and turnover $(\beta=-0.017, t=0.288, p=0.773)$ Therefore, hypothesis 7 was not supported in this study.

\section{DISCUSSIONS}

The above data analysis results indicated that organization embeddedness (OE) and community embeddedness (CE) totally can explain 36.7\% (in SEM2) variance of turnover intention among new generation of rural migrant workers in manufacturing sector. However, the totally explained variance modestly enhance to $38.2 \%$ (in SEM1), when the exogenous latent variables separated to the three sub-dimensions (i.e. organization embeddedness fit, links, and sacrifice; embeddedness links, fit, and sacrifice). When compared the predictive relevance $\left(\mathrm{Q}^{2}\right.$ ) of the path model between model 1(SEM1) and model 2 (SEM2), we found that the formative measurement model (SEM2) including OE and CE has a larger predictive relevance $\left(Q^{2}=0.342\right)$ than the reflective measurement model (SEM1) including OEF, OEL, OES and CEF, CEL, CES $\left(Q^{2}=0.287\right)$. These findings provided a view that job embeddedness is indeed a causal indicator model than reflective indicator model when conduct the research in the context of turnover.

Additionally, this study found the negative and significant relationship between OE ( $\beta=-0.355$, $\mathrm{t}=7.164, \mathrm{p}=0.000), \mathrm{CE}(\beta=-0.351, \mathrm{t}=6.581, \mathrm{p}=0.000)$ and turnover intention. The negative significant relationship between $\mathrm{OE}$ and turnover intention was consist with previous studies [16][19][20][21][22][23]. Meanwhile, the negative significant relationship between CE and turnover intention was consist with previous study [8][12][24]. Further compare the strength about the beta coefficients and $\mathrm{t}$-values of $\mathrm{OE}(\beta=-0.355, \mathrm{t}=7.164, \mathrm{p}=0.000)$ and $\mathrm{CE}(\beta=-0.351$, $\mathrm{t}=6.581, \mathrm{p}=0.000$ ) in predicting turnover, we can conclude that $\mathrm{OE}$ and $\mathrm{CE}$ are nearly sharing the same scores in predicting new generation of rural migrant workers' turnover intention in the manufacturing sector of China.

Furthermore, when we disaggregated the components of OE and CE into the three subdimensions, this study found same negative significant relationships between OEF ( $\beta=-0.394$, $\mathrm{t}=6.518, \mathrm{p}=0.000)$, OES $(\beta=-0.135, \mathrm{t}=2.012, \mathrm{p}=0.044), \operatorname{CEF}(\beta=-0.186, \mathrm{t}=3.279, \mathrm{p}=0.001), \operatorname{CES}($ $\beta=-0.277, \mathrm{t}=5.159, \mathrm{p}=0.000)$ and turnover intention. These results consist with previous studies [5], [15], [64]. However, a non-significant relationship ( $\beta=-0.017, \mathrm{t}=0.288, \mathrm{p}=0.773$ ) between CEL and turnover intention, The non-significant relationship between CEL and turnover intention is consist with prior studies[23].

Moreover, in consistent with previous study [5][15][64], this study found the relationship between OEL and turnover intention was positive ( $\beta=0.252, \mathrm{t}=4.080, \mathrm{p}=0.000)$. The positive relationship between OEL and turnover intention was consist with prior studies [15]. This finding shows that higher links increase intention to leave. This can be explained by the theory of social capital. According to social capital, social network can be classified it into "the strength of strong ties" and "the strength of weak ties" [65]. The strength of the social network an individual hold will absolutely impact on the acquisition of employment information and opportunities, thereby lead to higher job mobility [66]. In terms of rural migrant workers, who are defined as the peasants that come from rural area and engage in non-agricultural works in cities [67], they lived in rural villages before engaging in urban manufacturer. Their employment opportunities are relative limited, and primarily depended on the strength of 
strong ties, such as their family members and friends who have been worked in cities [65]. For new generation of rural migrant workers, the primary social capital that is linked to the kinship of ancestry is the first important means for them to obtain information in the city to find jobs in cities [65]. By utilizing the strength of strong ties of their relatives and friends, new generation of rural migrant workers find their first jobs in the city. At the same time, their relatives and friends who have been worked in urban cities might imply the strength of weak ties with the owners of the manufacturer or the peers in the same manufacturer and connected their social network to the urban members who owned resource in the cities. Thus, after obtaining jobs in the city, their own social capital will increase, but finally lead to high intention to quit because they have gained more employment information from the weak ties facilitating them find better jobs in another organization. Hence, having a good relationship with coworkers and supervisors, good attachment in departments of the organization, good job training opportunities provided by the organization, and long tenure of current working industry are associated with an individual's high organization links. These weak ties become the primarily approach that new generation of rural migrant workers gain further development in the urban cities. However, the strong ties of interaction between an individual and his/her friends, relatives who live in the same community show weak function for their further promotion in the urban city. In other words, new generation of rural migrant workers might show higher propensity to quit their current jobs as long as they can get help from these weak ties, when their strong ties did not help them to get a good job any more.

\section{RECOMMENDATIONS}

Firstly, by detailing the cultural and social difference in Chinese society, we found the distinct role of OEL and CEL in predicting new generation of rural migrant workers' turnover intention. Thus, human resource manager in the manufacturer might concern about the positive effect of OEL when they carry out management approach to new generation of rural migrant workers, because it might lead to high propensity to quit; Secondly, the results of current study were found in the context of new generation of rural migrant workers of China. Thus, future study could generalize it to different context and different industries. Thirdly, this study is a crosssectional study. A longitudinal methodology might be necessary to validate this study in future. Finally, this study used turnover intentions instead of actual turnover behaviors. Even though there were theoretical and empirical evidence demonstrating that turnover intention is the most proximal forecaster of voluntary turnover, the current study still ignored that individuals who do not plan to quit job but do leave because of internal or external events.

\section{References}

R. W. Griffeth, P. W. Hom, and S. Gaertner, "A Meta-Analysis of Antecedents and Correlates of Employee Turnover: Update, Moderator Tests, and Research Implications for the Next Millennium,” J. Manage., vol. 26, no. 3, pp. 463$488,2000$.

P. W. Hom and R. W. Griffeth, Employee turnover, OH: South-. Cincinnati, 1995.

C. P. Maertz and M. A. Campion, "25 years of voluntary turnover research: A review and critique.," Int. Rev. Ind. Organ. Psychol., vol. 13, pp. 49-83.

T. R. Mitchell and T. W. Lee, "The unfolding model of voluntary turnover and job embeddedness: Foundations for a comprehensive theory of attachment," Res. Organ. Behav., vol. 23, no. 0, pp. 189-246, 2001.

T. R. Mitchell et al., "Why people stay : using job embeddedness to predict voluntary turnover.," Acad. Manag. J., vol. 44, no. 6, pp. 1102-1121, 2001.

T. W. Lee et al., "The effects of job embeddedness on organizational citizenship , job performance , volitional absences , and voluntary turnover," Acad. Manag. J., vol. 47, no. 5, pp. 711-722, 2004.

B. C. Holtom, T. R. Mitchell, T. W. Lee, and M. B. Eberly, "Turnover and retention research: a glance at the past, a closer review of the present, and a venture into the future," Acad. Manag. Ann., vol. 2, no. 1, pp. 231-274, 2008. 
T. Lee, T. Burch, and T. Mitchell, "The story of why we stay: a review of job embeddedness," Annu. Rev. Organ. Psychol. Organ. Behav., vol. 1, no. 1, pp. 199-216, 2014.

J. P. Burton, B. C. Holtom, C. J. Sablynski, T. R. Mitchell, and T. W. Lee, "The buffering effects of job embeddedness on negative shocks," J. Vocat. Behav., vol. 76, no. 1, pp. 42-51, 2010.

M. Zhang, D. D. Fried, and R. W. Griffeth, "A review of job embeddedness: Conceptual, measurement issues, and directions for future research," Hum. Resour. Manag. Rev., vol. 22, no. 3, pp. 220-231, 2012.

K. Kiazad, B. C. Holtom, P. W. Hom, and A. Newman, “Job embeddedness: A multifoci theoretical extension,” J. Appl. Bus. Res., vol. 100, no. 3, pp. 641-659, 2015.

C. Tanova and B. C. Holtom, "Using job embeddedness factors to explain voluntary turnover in four European countries,” Int. J. Hum. Resour. Manag., vol. 19, no. 9, pp. 1553-1568, 2008.

V. Peltokorpi, “Job embeddedness in Japanese organizations," Int. J. Hum. Resour. Manag., vol. 24, no. 8, pp. 1551$1569,2013$.

W. S. Harman and M. Blum, "Albanian turnover: is the job embeddedness construct predictive in an albanian context?,” J. Behav. Appl. Manag., pp. 192-205, 2009.

M. Bambacas and C. T. Kulik, “Job embeddedness in China: how HR practices impact turnover intentions," Int. J. Hum. Resour. Manag., vol. 24, no. 10, pp. 1-20, 2012.

A. Ramesh and M. J. Gelfand, "Will they stay or will they go? The role of job embeddedness in predicting turnover in individualistic and collectivistic cultures.," J. Appl. Psychol., vol. 95, no. 5, pp. 807-823, 2010.

M. A. Darrat, D. A. Amyx, and R. J. Bennett, "Examining the impact of job embeddedness on salesperson deviance: The moderating role of job satisfaction," Ind. Mark. Manag., 2016.

C. Crossley, R. J. Bennet, S. M. Jex, and J. L. Burnfield, “Development of a global measure of job embeddedness and integration into a traditional model of voluntary turnover," J. Appl. Psychol., vol. 92, no. 4, pp. 1031-1042, 2007.

D. G. Allen, “Do organizational socialization tactics influence newcomer embeddedness and turnover?," J. Manage., vol. 32, no. 2, pp. 237-256, 2006.

C. M. Mallol, B. C. Holtom, and T. W. Lee, "Job embeddedness in a culturally diverse environment," J. Bus. Psychol., vol. 22, no. 1, pp. 35-44, 2007.

A. R. Wheeler et al., "Moderating and mediating the hrm effectiveness relationship," J. Manag. Issues, vol. 22, no. 2, pp. 182-196, 2010.

B. C. Holtom, D. R. Smith, D. R. Lindsay, and J. P. Burton, "The relative strength of job attitudes and job embeddedness in predicting turnover in a U . S . military academy," Mil. Psychol., vol. 26, pp. 397-408, 2014.

S. Ampofo, E. T., Coetzer, A., Susomrith, P., \& Rermlawan, “The job embeddedness-turnover intentions relationship: Evidence from Thailand.," 2017.

D. Ghosh and L. Gurunathan, "Do commitment based human resource practices influence job embeddedness and intention to quit?," IIMB Manag. Rev., vol. 27, no. 4, pp. 240-251, 2015.

J. Zhang, “Impact mechanism between knowledge-workers' organizational embeddedness, organizational commitment and organizational citizenship behavior(Chinese)," Tianjin University, 2011.

R. Liu, “A study on the job embeddness of the mid-high-end talents," Jinan University, 2011.

T. Yang and W. Lin, "Scale development of new generation migrant rural worker's job embeddedness:the moderating effect of community embeddedness(Chinese)," Population\&Economics, vol. 199, no. 4, pp. 21-29, 2013.

L. Xiaowei, J. Liao, and Q. Zeng, “An extended testing of voluntary turnover model --- Based on job embeddedness core staff organizational performance," Manage. World, no. 7, pp. 106-115, 2005.

Y. Li and L. Jun, "An empirical study of the impact of the perceived talent environmention performance and job embeddedness of the R\&D talents --taking 227 high-tech enterprise in shenzheng as example," Ruan Kexue, vol. 23, no. 8, pp. 110-114, 2009.

Y. Mai, G. Zou, and L. Mei, "The impact of job embeddedness on science and technology employees' entrepreneurial activity," Nankai Bus. Rev., vol. 12, no. 2, pp. 67-74, 2009.

A. C.Bluedorn, “A taxonomy of turnover,” Acad. Manag., vol. 3, no. 3, pp. 647-651, 1978. 
M. B. Eberly, D. Hall, and T. W. Lee, "Surveying the forest: A meta-analysis, moderator investigation, and futureoriented discussion of the antecedents of voluntary employee turnover.," Pers. Psychol., 2017.

D. G. Allen, P. C. Bryant, and J. M. Vardaman, "Retaining talent: replacing misconceptions with evidence-based strategies.," Acad. Manag. Perspect., vol. 24, no. 2, pp. 48-64, 2010.

J. Hausknecht and J. Holwerda, "When does employee turnover matter? Dynamic member configurations, productive capacity, and collective performance," Organ. Sci., vol. 24, no. 1, pp. 210-225, 2013.

D. Cho and J. Son, "Job embeddedness and turnover intentions : an empirical investigation of construction it industries," Int. J. Adv. Sci. Technol., vol. 40, pp. 101-110, 2012.

A. I. Kraut, "Predicting turnover of employees from measured job attitudes," Organ. Behav. Hum. Perform., vol. 13, no. 2, pp. 233-243, 1975.

R. P. Steel and N. K. Ovalle, "A review and meta-analysis of research on the relationship between behavioral intentions and employee turnover.," J. Appl. Psychol., vol. 69, no. 4, pp. 673-686, 1984.

Kirschenbaum\&Weisberg, "Predicting worker turnover: An assessment of intent on actual separations.," Hum. Relations, vol. 43, no. 9, pp. 829-847, 1990.

P. W. Hom and R. W. Griffeth, "Structural equations modeling test of a turnover theory: cross-sectional and longitudinal analyses," J. Appl. Psychol., vol. 76, no. 3, pp. 350-366, 1991.

P. W. Hom, T. R. Mitchell, T. W. Lee, and R. W. Griffeth, "Reviewing employee turnover: Focusing on proximal withdrawal states and an expanded criterion.," Psychol. Bull., vol. 138, no. 5, pp. 831-858, 2012.

I. Fishbein, M., \& Ajzen, Belief, attitude, intention, and behavior: An introduction to theory and research. Reading, MA: Addison-Wesley., 1975.

I. Ajzen, "The theory of planned behavior," Orgnizational Behav. Hum. Decis. Process., vol. 50, pp. 179-211, 1991.

W. H. Mobley, "Intermediate linkages in the relationship between job satisfaction and employee turnover," J. Appl. Psychol., vol. 62, no. 2, pp. 237-240, 1977.

H. A. March, J. G., \& Simon, Organizations. 1958.

R. M. Steer and R. T. Mowday, "Employee turnover and post decision accommodation process," Res. Organ. Behav., no. 3, pp. 235-281, 1981.

J. E. Sheridan and M. A. Abelson, "Cusp catastrophe model of employee turnover.," Acad. Manag. J., vol. 26, no. 3, pp. 418-436, 1983.

T. W. Lee and T. R. Mitchell, "An alternative approach : the unfolding model of voluntary employee turnover.," Acad. Manag., vol. 19, no. 1, pp. 51-89, 1994.

R. D. Iverson, "An event history analysis of employee turnover: the case of hospital employees in australia.," Hum. Resour. Manag. Rev., vol. 9, no. 4, pp. 397-418, 1999.

J. P. Hom, P. W., Lee, T. W., Shaw, J. D., \& Hausknecht, "One hundred years of employee turnover theory and research (Unpublished).," J. Appl. Psychol., 2017.

R. P. Steel and R. W. Griffeth, "The elusive relationship between perceived employment opportunity and turnover behavior: A methodological or conceptual artifact?," J. Appl. Psychol., vol. 74, no. 6, pp. 846-854, 1989.

C. S. Yao, X., Lee, T. W., Mitchell, T. R., Burton, J. P., \& Sablynski, “Job embeddedness: Current research and future directions. Understanding employee retention and turnover," pp. 153-187, 2004.

L. Ma and J. Han, "An analysis on the coordinated development of industrial upgrading and employment transformation of migrant workers in jiangsu province.," East China Econ. Manag., vol. 29, no. 5, pp. 23-27, 2015.

D. H. Perkins, "Rapid growth and changing economic structure: The expenditure side story and its implications for China," China Econ. Rev., vol. 23, no. 3, pp. 501-511, 2012.

P. Li and W. Li, "Economic status and social attitudes of migrant workers in China," China World Econ., vol. 15, no. 4, pp. 1-16, 2007.

F. Zhang, "A Study on the problem and countermeasure of migrant workers shortage--based on the perspective of migrant workers short - term employment," J. Theor., no. 1, pp. 74-76, 2016.

D. P. Bozeman and P. L. Perrewé, "The effect of item content overlap on Organizational Commitment Questionnaire-turnover cognitions relationships.," J. Appl. Psychol., vol. 86, no. 1, pp. 161-173, 2001. 
J. E. Moore, "One Road to Turnover: An Examination of Work Exhaustion in Technology Professionals," Misq, vol. 24, no. 1, p. 141, 2000.

R. W. Brislin, “Translation and content analysis of oral and written materials.,” Methodology, pp. 389-444, 1980.

D. George and M. Mallery, Using SPSS for Windows step by step: a simple guide and reference. 2003.

J. F. J. Hair, G. T. M. Hult, C. Ringle, and M. Sarstedt, A primer on partial least squares structural equation modeling (PLS-SEM). 2016.

J. F. Hair, C. M. Ringle, and M. Sarstedt, “PLS-SEM: Indeed a Silver Bullet,” J. Mark. Theory Pract., vol. 19, no. 2, pp. 139-152, 2011.

J. Henseler, C. M. Ringle, and R. Sinkovics, "The use of partial least squares path modeling in international marketing," Adv. Int. Mark., vol. 20, no. January, pp. 277-319, 2009.

J. Cohen, "Statistical Power Analysis for the Behavioral Sciences - 2nd Edition," Hillsdale, NJ Lawrence Erlbaum Assoc., pp. 8-14, 1988.

Y. Kim and Y. Kang, "The Relationship among Career Plateau, Self-efficacy, Job Embeddedness and Turnover Intention of Nurses in Small and Medium Sized Hospitals," Adv. Sci. Technol. Lett., vol. 14, no. 10, pp. 5078-5090, 2013.

P. Shen and M. Li, "Mechanism of social capital on stability of nearby employment for returned migrant workers and its countermeasures SHEN," Guangdong Agric. Sci., no. 23, pp. 207-212, 2015.

M. Granovetter, “The Strength of Weak Ties,” The American Journal of Sociology, vol. 78, no. 6. pp. 1360-1380, 1973.

State Council, "Several Suggestions on Countermeasure of Migrant Workers from State Council," State Council, 2006. 